\title{
Ultrasonography-guided penile block for adult penile surgery
}

\author{
Yavuz Gürkan, MD · Alparslan Kuş, MD • Can Aksu, MD • \\ Seyfettin Çiftçi, MD $\cdot$ Melih Çulha, MD $\cdot$ Pierre Pandin, MD
}

Received: 14 July 2015/Revised: 10 January 2016/Accepted: 21 January 2016/Published online: 28 January 2016

(c) Canadian Anesthesiologists' Society 2016

\section{To the Editor,}

Although penile nerve block (PNB) - both blind and ultrasound (US)-guided - has been established for clinical use, studies have focused more on children than adults. ${ }^{1-4}$ The analgesic effect of US-guided PNB in adult patients undergoing penile surgery has yet to be demonstrated. We report here its advantages in a randomized, blinded, clinical study.

After ethics committee permission (KOU KAEK 2013/ 117) and informed written consent, we enrolled 40 adult patients (20-60 yr, American Society of Anesthesiologists physical status I-II) scheduled for elective penile surgery (malleable prosthesis implant). Patients were randomized (sequentially numbered, opaque, sealed envelopes) to either spinal anesthesia + PNB (PNB) or spinal anesthesia alone (control) groups (20 patients per group). In a pilot study on "spinal only" patients, the mean (SD) $24 \mathrm{hr}$ postoperative morphine consumption was 28 (8) $\mathrm{mg}$. For $90 \%$ power and an alpha error of 0.05 , the sample size needed to detect a $30 \%$ difference was 18 subjects per group.

Y. Gürkan, MD · A. Kuş, MD

Department of Anesthesia, Kocaeli University Hospital, Kocaeli, Turkey

C. Aksu, MD ( $₫)$

Department of Anesthesia, Darıca Farabi State Hospital, Kocaeli, Turkey

e-mail: dr.aksu@gmail.com

S. Çiftçi, MD · M. Çulha, MD

Department of Urology, Kocaeli University Hospital, Kocaeli, Turkey

P. Pandin, MD

Department of Anesthesia, C.U.B Hôpital Erasme, Brussels, Belgium
With the patient in the lateral decubitus position, spinal anesthesia (25 G Quincke; B. Braun, Melsungen Germany) consisting of hyperbaric bupivacaine $10 \mathrm{mg}$ with fentanyl $25 \mu \mathrm{g}$ was used. Penile nerve block was subsequently performed using a high-frequency linear probe placed vertically over the pubic symphysis at the base of the penile shaft. Sagittal views identified the penile shaft, corpus cavernosum, inferior ramus of the pubic bone, and Scarpa's fascia. Using an out-of-plane approach under real-time US guidance, the block needle (Ultraplex, 22G; B. Braun, Melsungen, Germany) was advanced until it perforated Scarpa's fascia with a "pop." Then, $20 \mathrm{~mL}$ of $0.25 \%$ bupivacaine was injected in fractionated doses, with intermittent aspiration. For all patients, postoperative analgesia was provided with patient-controlled analgesia (morphine $1 \mathrm{mg}$ bolus, eight-minute lockout, maximum 6 $\left.\mathrm{mg} \cdot \mathrm{hr}^{-1}\right)$.

A pain nurse blinded to the anesthesia care performed postoperative follow-up. Pain (dynamic) was assessed at one, six, 12, and $24 \mathrm{hr}$ postoperatively using a visual analogue scale (VAS), where $0=$ no pain and $10=$ worst imaginable pain. The presence of nausea and vomiting were recorded at the same time intervals. Patient-controlled analgesia morphine consumption and the incidence of nausea and vomiting during the first $24-\mathrm{hr}$ postoperative period were also recorded. The Mann-Whitney U-test was used for comparison of VAS scores and morphine consumption between the two groups. The incidence of nausea and vomiting was compared using Fisher's exact test.

Anesthesia for both groups provided sufficient analgesia for the mean (SD) duration of surgery [PNB, 114 (45) min; control, 108 (38) min). The VAS scores and postoperative morphine consumption, however, were lower in the PNB group than in the control group at every time interval 
Table Postoperative VAS scores and morphine consumption during the first $24 \mathrm{hr}$ following surgery

\begin{tabular}{lllr}
\hline & Penile group $(n=20)$ & Control group $(n=20)$ & $P$ values \\
\hline VAS scores & & & 0.001 \\
$1^{\text {st }}$ hour & $0(0-0)^{*}$ & $2(0-4)$ & 0.011 \\
$6^{\text {th }}$ hour & $1.5(0-4)^{*}$ & $4(2-4)$ & $<0.001$ \\
$12^{\text {th }}$ hour & $0(0-2)^{*}$ & $3(2-4)$ & 0.001 \\
$24^{\text {th }}$ hour & $0(0-0)^{*}$ & $1(0-2)$ & $<0.001$ \\
Morphine consumption (mg) & & $1.5(1-2)$ & $<0.001$ \\
st hour & $0(0-0)^{* *}$ & $9(7-16)$ & $<0.001$ \\
$6^{\text {th }}$ hour & $1(0-3)^{* *}$ & $18(13-26)$ & $<0.001$ \\
$12^{\text {th }}$ hour & $5(1-8)^{* *}$ & $29(23-34)$ & \\
$24^{\text {th }}$ hour & $5(1-9)^{* *}$ & 6 & 0.091 \\
Postoperative complications $(n)$ & 1 & 4 & 0.342 \\
Nausea & 1 & & \\
Vomiting & 1 &
\end{tabular}

Data are presented as median (interquartile range) or patient numbers $(n)$

*VAS scores at all times were lower in the PNB group than in the control group

**Morphine consumption at all times was significantly higher in the control group than in the PNB group $(P<0.05)$

All patients who had vomiting received antiemetic medication (ondansetron $8 \mathrm{mg}$ iv)

$\mathrm{PNB}=$ penile nerve block; VAS = visual analogue scale

(Table). We showed that US-guided PNB in adult patients undergoing penile surgery confers postoperative analgesic benefit when this technique is combined with routine spinal anesthesia.

Conflicts of interest None declared.

\section{References}

1. Dalens B, Vanneuville $G$, Dechelotte P. Penile block via the subpubic space in 100 children. Anesth Analg 1989; 69: 41-5.
2. O'Sullvian MJ, Mislovic B, Alexander E. Dorsal penile nerve block for male pediatric circumcision - randomized comparison of ultrasoundguided vs anatomical landmark technique. Pediatric Anaesth 2011; 21: 1214-8.

3. Faraoni D, Gilbeau A, Lingier P, Barvais L, Engelman E, Hennart $D$. Does ultrasound guidance improve the efficacy of dorsal penile nerve block in children? Paediatr Anaesth 2010; 20: 931-6.

4. Sandeman DJ, Dilley AV. Ultrasound guided dorsal penile nerve block in children. Anaesth Intensive Care 2007; 35: 266-9. 